\title{
Early Administration of Low Molecular Weight Heparin after Spontaneous Intracerebral Hemorrhage
}

\author{
A Safety Analysis
}

\author{
Ines C. Kiphuth ${ }^{a}$ Dimitre Staykov ${ }^{a}$ Martin Köhrmann ${ }^{a}$ Tobias Struffert $^{b}$ \\ Gregor Richter $^{b}$ Jürgen Bardutzky ${ }^{a}$ Rainer Kollmar ${ }^{a}$ Mathias Mäurer ${ }^{a}$ \\ Peter D. Schellinger ${ }^{a}$ Max-Josef Hilz ${ }^{a}$ Arnd Doerfler ${ }^{b}$ Stefan Schwab ${ }^{a}$ \\ Hagen B. Huttner ${ }^{a}$
}

Departments of a Neurology and ${ }^{\mathrm{b}}$ Neuroradiology, University of Erlangen, Erlangen, Germany

\section{Key Words}

Intracerebral hemorrhage $\cdot$ Heparin $\cdot$ Hematoma growth

\begin{abstract}
Background: Venous thromboembolism (VTE) is a common complication after stroke. Application of low molecular weight heparins (LMWH) has been proven to be beneficial for the prevention of VTE in ischemic stroke patients. However, there is no consensus whether and how to administer LMWH for prevention of thrombotic complications after acute spontaneous intracerebral hemorrhage $(\mathrm{sICH})$, the main concern being possible hematoma growth. The objective of this study was to assess the safety of early subcutaneous $\mathrm{LMWH}$ in patients with $\mathrm{sICH}$ with respect to hemorrhage enlargement. Methods: A total of 97 patients with sICH were analyzed. LMWH (either enoxaparin-natrium or dalteparinnatrium) were initiated within $36 \mathrm{~h}$ after admission in all patients without clinical evidence of hemorrhage enlargement or an absence of evidence of hematoma growth on CT. Hematoma growth (significant when $>33 \%$, moderate when $>20 \%$ ) was assessed on follow-up CT between days 5 and 11 .
\end{abstract}

Results: None of the patients showed a significant hemorrhage growth. Between days 2 and 10, 2 patients experienced a moderate hematoma enlargement of 22.4 and $20.9 \%$. None of the included patients developed a fatal lung embolism. Conclusions: Early application of subcutaneous LMWH for prevention of venous thromboembolism seems to be safe, and probably does not increase the risk of hematoma growth in patients with $\mathrm{sICH}$.

Copyright $\odot 2008$ S. Karger AG, Basel

\section{Introduction}

Venous thromboembolism (VTE) is a common complication after hemorrhagic and ischemic stroke, and several risk factors such as age, adiposity, diabetes, immobility, hemiplegia and atrial fibrillation have been described [1]. The prevalence of objectively confirmed hospital-acquired deep vein thrombosis (DVT) in patients not receiving thromboprophylaxis is up to $20 \%$ in stroke and critical care patients, increasing the risk of pulmonary embolism (PE) [2-5]. After acute ischemic stroke, the ad-

\section{KARGER}

Fax +4161306 1234 E-Mail karger@karger.ch www.karger.com
(ㄷ) 2008 S. Karger AG, Basel

1015-9770/09/0272-0146\$26.00/0

Accessible online at:

www.karger.com/ced
Dr. H.B. Huttner

Department of Neurology, University of Erlangen

Schwabachanlage 6

DE-91054 Erlangen (Germany)

Tel. +49 9131854 4523, Fax +49 9131853 1160, E-Mail hagen.huttner@uk-erlangen.de 
ministration of subcutaneous anticoagulants is recommended to prevent DVT among immobilized patients $[1$, $6,7]$, the use of low molecular weight heparin (LMWH) being superior to unfractionated heparin [8].

In contrast to patients with ischemic stroke, in spontaneous intracerebral hemorrhage (sICH) there are: (1) less data on thromboembolic complications, and (2) up till now, no consentaneous guidelines on how to prevent VTE [9]. A comprehensive data analysis by Skaf et al. [10] identified $3.98 \%$ of thrombotic complications in $1,606,000$ patients with ICH (PE in $0.68 \%$, DVT in $1.37 \%$, VTE in 1.93\%). Maramattom et al. [11] reported 2 confirmed cases of PE in $144 \mathrm{ICH}$ patients (1.4\%), and Gregory and Kuhlemeier [12] diagnosed DVT in $1.9 \%$ of $1,926 \mathrm{ICH}$ patients. In line with these studies, the prospective randomized trial on activated recombinant factor VII (rFVIIa; NOVO7) showed $2 \%$ of serious thromboembolic events in both the placebo and rFVIIa-treated group [13].

Nevertheless, there is no consensus on how to avoid thrombotic complications after ICH [9]. Anticoagulants, platelet antiaggregants, unfractionated and LMW heparins as well as the use of mechanical methods, such as intermittent pneumatic compression [14] and graduated compression stockings, are options with varying levels of evidence in preventing VTE [9]. Although 2 small prospective studies $[15,16]$ and 1 retrospective analysis [17] regarding the use of heparin in sICH have been published - none of them was associated with an increased risk of secondary bleeding - debate remains whether it is safe to administer unfractionated or LMW heparins to sICH patients. In particular, physicians continue to be concerned about possible hematoma growth in patients with sICH receiving heparins $[18,19]$, and the neurosurgical guidelines still discourage the use of heparin in intracranial hemorrhage [20].

The aim of the present study was to analyze the safety of early administered LMWH in sICH patients with regard to hematoma growth.

\section{Methods}

\section{Patient Selection}

The source of this retrospective and observational study was a prospectively organized database of our department, in which clinical and neuroradiological data of consecutive patients with sICH and who were treated in our stroke and neurocritical care unit between February 2006 and December 2007 had been entered. To be enrolled into the present analysis on the safety of LMWH with regard to hematoma growth, patients had to fulfill the following criteria: (1) brain imaging at 3 time points, i.e. presence of baseline imaging (CT or MRI), follow-up imaging $24 \pm$ $6 \mathrm{~h}$ after baseline, and control CT, between days 5 and 11, and (2) administration of LMWH started after the 24-h control CT without evidence of hematoma growth. Ninety-seven patients fulfilled these criteria. We did not enroll patients with evidence of subdural, epidural or subarachnoid hemorrhages, or hemorrhage related to trauma, tumor, thrombolysis, arteriovenous malformations or oral anticoagulant treatment. Furthermore, patients were not analyzed if they: (1) underwent surgery for hematoma evacuation; (2) received a 'do not resuscitate' or 'do not treat' order initially or within $24 \mathrm{~h}$ because of a combination of age, hemorrhage volume, severe co-morbidity and absent consent of relatives for neurocritical care; (3) who showed evidence of moderate or significant hemorrhage growth (for definition, see 'Hemorrhage Growth') on the follow-up CT $24 \mathrm{~h}$ after admission; (4) did not receive follow-up imaging according to the above-mentioned criteria, and received other medication or treatment than LMWH for prophylaxis of VTE.

\section{Clinical Management and Application of LMWH}

Patients with sICH were treated according to the EUSI recommendations [21]. An external ventricular drain was inserted in all patients with evidence of occlusive hydrocephalus. Within $36 \mathrm{~h}$ after admission all 97 patients received subcutaneous LMWH once a day. From February 2006 until January 2007, 4,000 IU enoxaparin-natrium was given, and from February 2007 to December 2007 patients received 2,500 IU dalteparin-natrium, according to the manufacturers' recommendations. The switching to dalteparin-natrium was based on an institutional protocol of our hospital pharmacy department regarding the prophylactic use of LMWH for prevention of VTE.

\section{Imaging}

ICH was diagnosed immediately after hospital admission by CT or MRI. In cases of lobar and posterior fossa bleeding, patients underwent either CT, MR angiography or digital subtraction angiography to rule out an underlying cause of the hemorrhage (e.g. arteriovenous malformation). The hematoma site was categorized into deep (basal ganglia and thalamic hemorrhages), lobar, cerebellar and brainstem hematoma. ICH volume was calculated using the formula for ellipsoids $(\mathrm{ABC} / 2)[22,23]$. Regarding the low reliability and feasibility of quantitative volumetry in ventricular hemorrhages [24], the intraventricular blood portion was not considered for hematoma volume measurement.

\section{Hemorrhage Growth}

Significant hemorrhage growth was defined as an increase in the volume of the parenchymal hematoma of $>33 \%$, as measured by image analyses of follow-up CT compared to the baseline scan [25]. Moderate hemorrhage growth was defined as an increase in hematoma volume of $>20 \%$.

Statistical Analysis

Statistical analyses were performed using the SPSS software package version 13.0 (SPSS, Chicago, Ill. USA). The Shapiro-Wilk test was used to determine the distribution of the data. Normally distributed data are expressed as means $\pm \mathrm{SD}$, other data are expressed as medians and ranges. 
Table 1. Clinical and radiological parameters of the 97 patients included

\begin{tabular}{lc}
\hline Patient characteristics & \\
Age (median), years & $68(35-95)$ \\
Males/females, $\mathrm{n}$ & $57 / 40$ \\
GCS on admission (median) & $10(3-15)$ \\
\hline Imaging findings & \\
Volume, $\mathrm{cm}^{3}$ & $33.47 \pm 20.70$ \\
Location, $\mathrm{n}$ & \\
$\quad$ Deep (ganglionic and thalamic) & $54(56)$ \\
$\quad$ Lobar & $27(27)$ \\
$\quad$ Cerebellar & $5(5)$ \\
$\quad$ Brainstem & $11(12)$ \\
Intraventricular hemorrhage, $\mathrm{n}$ & $60(63)$ \\
External ventricular drain, $\mathrm{n}$ & $33(36)$ \\
\hline
\end{tabular}

Figures in parentheses are ranges or percentages.

GCS = Glasgow Coma Scale.

Table 2. Patient characteristics, clinical data and imaging findings of the 2 patients with moderate hematoma growth

\begin{tabular}{lll}
\hline & Patient 1 & Patient 2 \\
\hline Age, years & 84 & 91 \\
Gender & male & female \\
GCS score (on admission) & 13 & 14 \\
NIHSS score (on admission) & 6 & 17 \\
\hline Anticoagulant received & enoxaparin & dalteparin \\
\hline Volume, cm & & \\
$\quad$ Baseline & & \\
$\quad$ 24-h follow-up & 59.2 & 27.1 \\
$\quad$ Day 7 (patient 1)/day 9 (patient 2) & 73.6 & 35.8 \\
Hematoma growth, \% & & \\
$\quad$ between 24-h scan and days 7-9) & 20.9 & 22.4 \\
Ventricular involvement & no & yes \\
External ventricular drain & no & no \\
Clinical worsening & day 7 & unapparent \\
Location & lobar & basal ganglia \\
\hline GCS score (discharge) & 13 & 13 \\
NIHSS score (discharge) & 9 & 17 \\
\end{tabular}

GCS = Glasgow Coma Scale; NIHSS = National Institutes of Health Stroke Scale.

\section{Results}

For patient characteristics, clinical data and imaging findings of the 97 patients included, please refer to table 1 . The median National Institutes of Health Stroke Scale

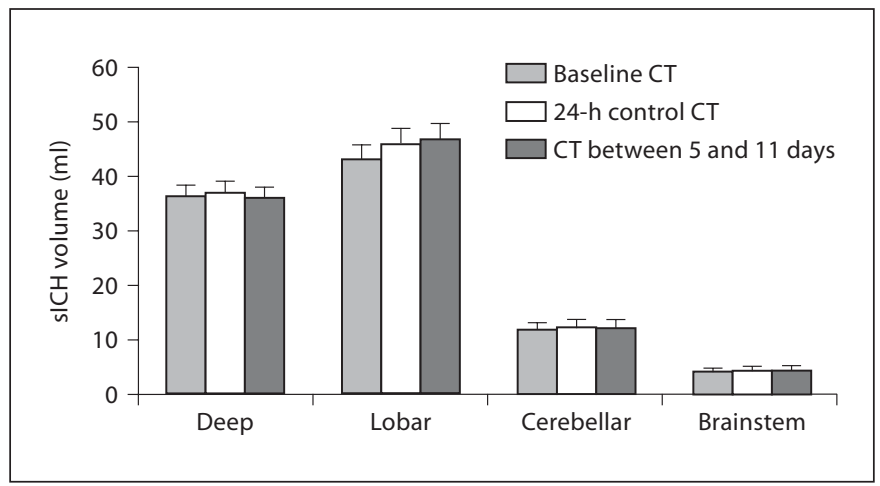

Fig. 1. Mean \pm SEM hematoma volumes of the 97 patients included.

score on admission was 14 (1-31). Forty-one patients (42\%) received enoxaparin-natrium and 56 patients $(58 \%)$ dalteparin-natrium. After initiation of subcutaneous LMWH on day 2, none of the patients developed a significant hemorrhage growth $>33 \%$. Figure 1 shows the mean hematoma volumes of all patients during the course of treatment.

Two patients showed a moderate increase in hematoma volume of $>20 \%$ (22.4 and 20.9\%). Patient characteristics, clinical data and imaging findings of these patients are given in table 2 .

It was beyond the scope of this study to investigate possible benefits of LMWH on the frequency of VTE, DVT and PE; however, at least it can be stated that in this series none of the patients died from PE, nor had clinical or electrocardiological evidence of severe PE. Two patients developed heparin-induced thrombocytopenia and anticoagulation was switched to hirudin.

\section{Discussion}

This study on the safety of LMWH in the acute stages of sICH is the first of its kind and contributes to the ongoing debate on how to best prevent possible VTE in hemorrhagic stroke patients. As the key finding, early administration of LMWH was not associated with an increased risk of parenchymal hematoma growth.

Two key points have emerged from our data. First, hematoma growth and rebleeding beyond the 24-h time window after the initial event are less frequent in sICH compared to other ICH populations, e.g. ICH related to oral anticoagulant treatment [18, 25-27] - Lim et al. [19] reported significant hematoma growth $(>50 \%)$ in $0.9 \%$ of 
sICH patients between days 2 and 7. Consistent with that study and similar findings reported previously [18], 2 out of the 97 patients analyzed here (i.e. 2.06\%) showed moderate growth of $>20 \%$. A significant hemorrhage enlargement - according to the widely accepted definition by Brott et al. [25] - was not observed in our series. Hence, the frequency of hemorrhage enlargement was not different from these previous studies on incidence of rebleeding in ICH without application of LMWH $[18,19]$. In line with earlier findings for unfractionated heparins $[15,16]$, LMWH do not seem to be associated with an elevated bleeding tendency in $\mathrm{sICH}$, as long as given subcutaneously for thromboprophylaxis.

Second, the benefit of subcutaneous heparins, especially the easily applicable LMWH, for prevention of VTE and $\mathrm{PE}$ has previously been proven for a variety of diseases $[4,8,28]$. Although not investigated in a randomized and controlled design, LMWH are also likely to show positive effects in ICH patients in terms of VTE prevention. While severe thromboembolic complications occur in about $2 \%$ of ICH patients [10-13], physicians, however, still refrain from giving $\mathrm{LMWH}$ in sICH due to concern of possible rebleeding and hematoma growth, which led to class I guidelines (level of evidence B) recommending intermittent pneumatic compression for the prevention of embolic complications [9]. In the light of only a few existing studies addressing the issue of VTE prevention in $\mathrm{sICH}$, our findings should contribute to a less anxious application of subcutaneously administered LMWH in sICH patients. A prospective randomized controlled analysis on the safety of LMWH, including efficacy aspects, appears warranted to expand the knowledge in this field.

Our study has certain shortcomings because of the nonrandomized and noncontrolled retrospective design. The lack of a priori determined time points for imaging controls results in only limited information regarding safety of LMWH in terms of hemorrhagic complications other than hematoma growth. In addition, we did not analyze the efficacy of LMWH with respect to frequency of VTE, PE and sonography-based diagnosis of DVT. Moreover, other factors possibly impacting the occurrence of hematoma growth, e.g. mean arterial pressure, were not investigated. Finally, in those patients who required an external ventricular drain, a possible hemorrhage enlargement within the ventricles was not analyzed.

In conclusion, our data suggest that subcutaneous administration of LMWH starting subsequently to a control CT $24 \mathrm{~h}$ after disease onset is probably not associated with an increased risk of hematoma growth in sICH patients. A prospective safety and efficacy study of LMWH for prevention of VTE in sICH patients seems indicated.

\section{References}

1 Adams HP Jr, del Zoppo G, Alberts MJ, et al: Guidelines for the early management of adults with ischemic stroke: a guideline from the American Heart Association/American Stroke Association Stroke Council, Clinical Cardiology Council, Cardiovascular Radiology and Intervention Council, and the Atherosclerotic Peripheral Vascular Disease and Quality of Care Outcomes in Research Interdisciplinary Working Groups: the American Academy of Neurology affirms the value of this guideline as an educational tool for neurologists. Stroke 2007;38:1655-1711.

2 Gubitz G, Sandercock P, Counsell C: Anticoagulants for acute ischaemic stroke. Cochrane Database Syst Rev 2004;CD000024.

3 Sandercock P, Counsell C, Stobbs SL: Lowmolecular-weight heparins or heparinoids versus standard unfractionated heparin for acute ischaemic stroke. Cochrane Database Syst Rev 2005;CD000119.
4 Geerts WH, Pineo GF, Heit JA, et al: Prevention of venous thromboembolism: the Seventh ACCP Conference on Antithrombotic and Thrombolytic Therapy. Chest 2004; 126(suppl):S338-S400.

5 Wijdicks EF, Scott JP: Pulmonary embolism associated with acute stroke. Mayo Clin Proc 1997;72:297-300.

6 Diener HC, Ringelstein EB, von Kummer R, et al: Prophylaxis of thrombotic and embolic events in acute ischemic stroke with the lowmolecular-weight heparin certoparin: results of the PROTECT Trial. Stroke 2006;37: 139-144.

7 Clagett GP, Anderson FA Jr, Heit J, Levine MN, Wheeler HB: Prevention of venous thromboembolism. Chest 1995;108(suppl): S312-S334.

8 Sherman DG, Albers GW, Bladin C, et al: The efficacy and safety of enoxaparin versus unfractionated heparin for the prevention of venous thromboembolism after acute ischaemic stroke (PREVAIL Study): an open-label randomised comparison. Lancet 2007; 369:1347-1355.
9 Broderick J, Connolly S, Feldmann E, et al: Guidelines for the management of spontaneous intracerebral hemorrhage in adults: 2007 update: a guideline from the American Heart Association/American Stroke Association Stroke Council, High Blood Pressure Research Council, and the Quality of Care and Outcomes in Research Interdisciplinary Working Group. Stroke 2007;38:2001-2023.

10 Skaf E, Stein PD, Beemath A, Sanchez J, Bustamante MA, Olson RE: Venous thromboembolism in patients with ischemic and hemorrhagic stroke. Am J Cardiol 2005;96: 1731-1733.

11 Maramattom BV, Weigand S, Reinalda M, Wijdicks EF, Manno EM: Pulmonary complications after intracerebral hemorrhage. Neurocrit Care 2006;5:115-119.

12 Gregory PC, Kuhlemeier KV: Prevalence of venous thromboembolism in acute hemorrhagic and thromboembolic stroke. Am J Phys Med Rehabil 2003;82:364-369. 
13 Mayer SA, Brun NC, Begtrup K, et al: Recombinant activated factor VII for acute intracerebral hemorrhage. N Engl J Med 2005; 352:777-785.

14 Lacut K, Bressollette L, Le Gal G, et al: Prevention of venous thrombosis in patients with acute intracerebral hemorrhage. Neurology 2005;65:865-869.

15 Boeer A, Voth E, Henze T, Prange HW: Early heparin therapy in patients with spontaneous intracerebral haemorrhage. J Neurol Neurosurg Psychiatry 1991;54:466-467.

16 Dickmann U, Voth E, Schicha H, Henze T, Prange H, Emrich D: Heparin therapy, deep-vein thrombosis and pulmonary embolism after intracerebral hemorrhage. Klin Wochenschr 1988;66:1182-1183.

17 Kleindienst A, Harvey HB, Mater E, et al: Early antithrombotic prophylaxis with low molecular weight heparin in neurosurgery. Acta Neurochir (Wien) 2003;145:1085-1090, discussion 1090-1081.

18 Kazui S, Naritomi H, Yamamoto H, Sawada T, Yamaguchi T: Enlargement of spontaneous intracerebral hemorrhage: incidence and time course. Stroke 1996;27:1783-1787.
19 Lim JK, Hwang HS, Cho BM, et al: Multivariate analysis of risk factors of hematoma expansion in spontaneous intracerebral hemorrhage. Surg Neurol 2008;69:40-45.

20 Browd SR, Ragel BT, Davis GE, Scott AM, Skalabrin EJ, Couldwell WT: Prophylaxis for deep venous thrombosis in neurosurgery: suggested DVT prevention guidelines. Neurosurg Focus 2004;17:E1.

21 Steiner T, Kaste M, Forsting M, et al: Recommendations for the management of intracranial haemorrhage. 1. Spontaneous intracerebral haemorrhage: the European Stroke Initiative Writing Committee and the Writing Committee for the EUSI Executive Committee. Cerebrovasc Dis 2006;22:294-316.

22 Kothari RU, Brott T, Broderick JP, et al: The $\mathrm{ABCs}$ of measuring intracerebral hemorrhage volumes. Stroke 1996;27:1304-1305.

23 Huttner HB, Steiner T, Hartmann M, et al: Comparison of $\mathrm{ABC} / 2$ estimation technique to computer-assisted planimetric analysis in warfarin-related intracerebral parenchymal hemorrhage. Stroke 2006;37:404-408.

24 Zimmerman RD, Maldjian JA, Brun NC, Horvath B, Skolnick BE: Radiologic estimation of hematoma volume in intracerebral hemorrhage trial by CT scan. AJNR Am Neuroradiol 2006;27:666-670.
25 Brott T, Broderick J, Kothari R, et al: Early hemorrhage growth in patients with intracerebral hemorrhage. Stroke 1997;28:1-5.

26 Flibotte JJ, Hagan N, O’Donnell J, Greenberg SM, Rosand J: Warfarin, hematoma expansion, and outcome of intracerebral hemorrhage. Neurology 2004;63:1059-1064.

27 Audebert HJ, Schenk B, Tietz V, Schenkel J, Heuschmann PU: Initiation of oral anticoagulation after acute ischaemic stroke or transient ischaemic attack: timing and complications of overlapping heparin or conventional treatment. Cerebrovasc Dis 2008;26: 171-177.

28 Dolovich LR, Ginsberg JS, Douketis JD, Holbrook AM, Cheah G: A meta-analysis comparing low-molecular-weight heparins with unfractionated heparin in the treatment of venous thromboembolism: examining some unanswered questions regarding location of treatment, product type, and dosing frequency. Arch Intern Med 2000;160:181-188. 